\title{
Too Smart to Participate? Rational Reasons for Employees' Non-participation in Action Research
}

\author{
Kristin Lebesby ${ }^{1}$ (D) Jos Benders ${ }^{1,2}$ (D) \\ Received: 19 March 2020 / Revised: 15 June 2020 / Accepted: 18 June 2020 / \\ Published online: 29 June 2020 \\ (C) The Author(s) 2020
}

\begin{abstract}
Action research literature promotes broad participation in order to gain better insights into prevailing issues and cope with both present and future challenges in organizations. For good reasons, action researchers view participation as desirable and even necessary. However, emphasizing participation also creates a blind spot: researchers tend to assume that employees are willing or even eager to take part in organizational change projects. A group of action researchers involved in a large-scale organizational development project in a Norwegian public organization initially also had this optimistic assumption. Over time, they realized that many employees were reluctant to participate and often kept silent, so they conducted follow-up research to explore the reasons for employees' non-participation. The findings show that the employees had rational reasons not to participate, and that employee participation should not be taken for granted. The paper outlines eight different rationales for non-participation, and discusses implications for action research.
\end{abstract}

Keywords Employee participation · Action research · Organizational development - Resistance to change

\section{Introduction}

Organizations encourage employee participation in decision-making processes in order to enhance productivity, creativity and competitiveness (Cheney 1995; Deetz 1992; Harrison and Freeman 2004; McLagan and Nel 1995). Action researchers often promote bringing together of action and reflection, as well as theory and practice in order to ensure a better understanding of prevailing issues and realize changes (Eikeland 2012; Greenwood and Levin

Kristin Lebesby

kristin.lebesby@ntnu.no

1 Department of Industrial Economics and Technology Management, Norwegian University of Science and Technology (NTNU), Trondheim, Norway

2 CESO, KU Leuven, Leuven, Belgium 
2007; Gustavsen 2017; Reason and Bradbury 2001). Participation is fundamental for any action research (AR) project, whereby a strong focus is placed on soliciting the input of the less privileged and less powerful into collective design and development projects. Ideally, all project participants must be given an opportunity to freely and openly express themselves (Greenwood and Levin 2007; Reason 2014; Reason and Bradbury 2001).

Humankind would not be able to make progress without ideals. However, fully realizing ideals is often impossible. This also holds for participation in AR-inspired projects, particularly those within organizations. In this paper, we consider how action researchers' implicit assumption that employees want to participate was challenged in a large-scale organizational development project in a Norwegian public organization. At the outset of the project, managers and action researchers strived to adapt their approaches and the design according to the ideals of AR. By involving management, unions and employees in the development project, the organization hoped to strengthen their collective learning, knowledge sharing and acquisition of new competencies. Over time, it was found that many employees were reluctant to participate and often kept silent. This paper aims to explore the reasons behind this. Thus, the research question is: Why would employees withhold their participation in AR? Based on data analysis, this paper outlines eight different rationales for non-participation and discusses implications for AR.

Earlier, Neumann (1989) addressed the theme of employee participation in organizational change. She challenged the pre-disposition that prospective participants ought to desire to participate and if they do not, something must be wrong with them. Instead of blaming nonparticipation to psychological deficiencies or 'irrationality', Neumann pointed to barriers to participate at various levels. In a similar vein as Dent and Goldberg (1999) did for 'resistance to change', she plead to look at concrete situation and analyze for what reasons employees withhold participation. We leave from the same position as Neumann, yet focus at individual employees with a specific AR-inspired change project. Our critique is meant constructively. As Neumann argued: "While religious, political and economic fervor has brought participation to its current "state of the art," this same fervor threatens to limit further development" (1989: 184). Participation can only be stimulated if barriers to participation are understood.

\section{AR and Employee Participation}

Although Reason and Bradbury (2001) point out that there is no simple way of defining AR, its well-known core characteristics are participation, democratic processes and knowledge development. The primary purpose of $\mathrm{AR}$ is to produce knowledge that can be used in everyday life. From this perspective, action and reflection are closely connected, in the same way that theory and action are (Reason and Bradbury 2001). The reasons for employee participation are well represented in the AR literature. AR promotes researcher participation and working together with other participants (Eikeland 2012; Greenwood and Levin 2007; Gustavsen 2017; Reason and Bradbury 2001). In the Handbook of Action Research (Reason and Bradbury 2001: 2), it is stated that AR is only possible with, for and by persons and communities, and that it ideally involves all stakeholders both in the questioning and sensemaking that informs the research, and in the action that is in its focus.

An ideal outcome of AR is for local participants to gain greater control over their own situation as a group and for changes to be perceived as real and meaningful (Greenwood and 
Levin 2007; Hall 2001). To Lewin (in Kristiansen and Bloch-Poulsen 2017), participation, change and action research in organizations were intimately connected because he understood action research as an inquiry that creates changes through participation. Through democratic participation in knowledge production, people who are otherwise marginalized are given a stronger voice and greater agency, and have an opportunity to take action in order to transform power and social relations in the process (Gaventa and Cornwall 2006). It is important to note that there are different perspectives and definitions of participation in organizational change (Busck et al. 2010; Pateman 1970; Wenger 1998). In a cooperative research context, the researcher's role is to support practitioners in analyzing and interpreting their own data to inform new behaviors (Baldwin 2002). In the case of organizational development efforts and broad participation, action researchers strive for equal participation and democratic processes (Godden 2017; Greenwood and Levin 2007; Reason 1999). Table 1 shows three main categories of motivation to participate derived from the literature.

Table 1 illustrates how AR perspectives constitute an organizational viewpoint. The literature proposes that both the organization as a whole and clients will benefit from AR efforts (Greenwood and Levin 2007). However, if the perspectives of individual workers were taken into account, the table would look very different. While there are strong arguments for employee participation, the proverb "you can bring a horse to the water but can't make it drink" holds here as well. Despite the proclaimed benefits, employees may be reluctant to constructively engage in organizational change.

As action researchers are often intimately involved in change projects, they are frequently confronted with challenges, such as bridging the gaps between different ways of thinking between researchers and practitioners (Titchen and Binnie 1993), limited generalization (Brydon-Miller et al. 2003), the extensive amount of resources needed (Simonsen 2009), and the researchers' role throughout the AR processes (Baskerville 1997; Melin and Axelsson 2016; Mumford 2001). In addition, Friedman (2001) pointed to the need for participants to acquire complex skills of reasoning and behavior, which requires considerable time, effort, and commitment; skillful instruction; and specific set of conditions that rarely exist in real-life settings. Connected to nurses' experiences of engaging in participatory AR, Dewing and Traynor (2005) found that for some participants there was a sense of AR being done to them rather than with them. They also found that the lack of skills among researchers and practitioners, might inhibit the possibility of critical reflections on current ways of working and the awareness of power and conflict situations in groups. AR has also encountered some challenges connected to diffusion. Working with "search conferences", the goal has been to

Table 1 Motivation for employee participation in action research (AR)

\begin{tabular}{ll}
\hline AR perspective & Motives \\
\hline Reflection & Sharing knowledge \\
& Questioning current practices \\
Action & Joint efforts between practitioners and researchers \\
& Improving current practices collectively \\
Democracy & Developing improved services \\
& Broad participation \\
& Opportunity to make suggestions for improvement \\
& Having a say in the decision-making \\
& Creating joint vision(s) \\
\hline
\end{tabular}


ensure equal access to the surrounding world for all concerned (Emery and Purser 1995). However, the assumption that all organizational members confront the same reality has become problematic (Gustavsen and Pålshaugen 2015).

The reasons for participation as outlined above are important, and we fully subscribe to the principle that stakeholder participation, especially of the less powerful among them, should be fostered. Yet, as Neumann (1989) argued, this principle may achieve an ideological status, and the spotlight put on participation creates blind spots at the same time: 'To refuse investigation into practical difficulties into one's favored approach condemns that approach to stagnation' (1989: 383). An implicit assumption that participants will not have good reasons for withholding their participation might inhibit the intended processes and results.

\section{Methods}

The data were gathered over the course of two years (2016-2018) as part of an AR project in a large Norwegian public organization. This included the $\mathrm{PhD}$ project of the first author, who had access to data from both projects.

The data used in this paper (see Table 2) are part of a larger archive and consist of (1) field notes from observing project activities over the two-year period and (2) transcribed semistructured and group interviews. In total, four researchers were involved in the project; of them, the first author of this paper gathered data as part of her PhD project, while the other action researchers had a more active role in planning, providing conceptual and theoretical tools, and interacting with the practitioners. It is important to clarify that the first author joined the research project at a time when the project had already been designed and was already under way. The other three researchers can be defined as 'friendly outsiders' (Greenwood and Levin 2007), while the first author had an observant role. The total body of data is the result of all researchers' efforts to collect field notes and organize interviews with managers, union representatives and participants of the development project.

The interviews were not guided by predetermined research questions; the intention was rather to collect the participants' own narratives of experiences during the development project. Through conducting interviews and observing project activities, the issue of nonparticipation forced itself to the foreground and came into focus. The challenge was then to find the reasons for non-participation. The quotes in this paper come from participants' own

Table 2 Data gathered

\begin{tabular}{lcc}
\hline & PhD project & Action research project \\
\hline Initial group interviews & & 4 (managers) \\
& & 2 (employees) \\
$\begin{array}{l}\text { Semi-structured interviews with } \\
\text { participants }\end{array}$ & $\begin{array}{c}\text { (employees, including } 3 \text { union } \\
\text { representatives) }\end{array}$ & \\
$\begin{array}{l}\text { Group interviews } \\
\text { Observation of manager seminars }\end{array}$ & 6 (employees) \\
Observation of pilot projects & All 8 workshops 8 for two local pilot & (local managers) \\
& projects & (union representatives) \\
& & pilots
\end{tabular}


narratives and experiences with the project, and are not answers to direct questions about their reasons for non-participation. Drawing upon Gioia et al. (2013), Table 3 illustrates the process of breaking down data into concepts, themes and dimensions.

The analysis of the interviews showed that there were eight recurring reasons why employees did not want to participate in the AR: fear of job loss, negative feedback, pseudo participation, belief that knowledge is power, cost of participation, efforts to participate, belief that giving suggestions leads to more work and lack of instrumental reason to participate. These eight themes were then aggregated into four dimensions (see Table 3).

\section{A Norwegian Public Organization}

In November 2014, several Norwegian unions initiated trial projects in large organizations in order to improve the quality of their services to the benefit of both employees and clients. One of the invited organizations that took part was a large public organization. Its human resources department found that the individual training of its employees did not have the desired effects

Table 3 Analysis of transcribed data

\begin{tabular}{llc}
\hline First-order concepts & Second-order themes & $\begin{array}{c}\text { Aggregated } \\
\text { dimensions }\end{array}$ \\
\hline - Developing and changing job descriptions & Fear of job loss & Political pressures \\
- Multidisciplinarity reduces the need for workers & & $\begin{array}{l}\text { to become more } \\
\text { effective }\end{array}$
\end{tabular}

- An employee is threatened when reporting something Negative feedback

Power issues

- When the management and employees disagree on development actions, employees risk rejection

- Giving improvement suggestions does not change anything

- Decisions have been already made

- Union-management cooperation is just a charade

- Decision-making is a top-down process

- Sharing knowledge is not conceived as beneficial to the individual worker because they risk losing their advantages

Belief that knowledge is power

- Managers are not inclined to share information/responsibilities

- Workers are protecting their (power) positions

- Action research efforts are time consuming

- The resources required are comprehensive

- Participation requires a different mindset

- AR project is conceived as cumbersome

- Employees are unfamiliar with intangible concepts

- Improvement suggestions are extra work

- Workers have to 'do it themselves'

- Participation is not rewarded separately

No reason to put in extra effort if it is not rewarded

- Those putting in the extra effort help colleagues without

Pseudo participation being rewarded for it

- Workers are satisfied with the status quo

$\begin{array}{ll}\text { Cost of participation } & \begin{array}{l}\text { Demanding } \\ \text { parallel project }\end{array} \\ \text { Efforts to participate } & \end{array}$

Belief that giving suggestions AR efforts entail leads to more work going beyond Lack of instrumental reasons established work to participate descriptions 
in terms of knowledge sharing, collective learning and acquisition of new competencies. The management, union representatives and employees wanted to establish closer cooperation between different levels and functional groups within the organization, and to strengthen labor-management cooperation.

The human resources department was given the task of designing a development project with the appointed management group, which would be presented and implemented in their department (TVD) in the Eastern region of Norway. TVD employed approximately 500 employees, covering a range of professional departments and geographically divided traffic stations. In recent years, the organization had undergone some structural changes, which were a source of uncertainty and unpredictability for both local managers and employees. The project, called "TVD-development" lasted from 2015 to the end of 2017. Its focus was to improve existing practices in TVD, with a focus on the following five themes: service, reputation, exercise of authority, traffic safety and client interaction.

The project was divided into four parts. First, the project management group put together six interdisciplinary groups, the goal of which was to make employees go out and interview their own colleagues in order to collect best practices within the themes. The participants generally seemed to perceive this part of the project as meaningful and motivating. Secondly, management development seminars were organized in order to train managers to work with four theoretical perspectives for analyzing their practices. Third, local development pilot projects were conducted at six different traffic stations and functional groups. The fourth part consisted of collaborating with the action researchers, who were facilitating the process. The action researchers had the role of "friendly outsiders", who advised project managers, contributed with theoretical perspectives and joined the conversations. At the end, the researchers wrote the final report.

The number of participants in the pilots varied between six and 20 employees from two main functional groups. The first, called the "mercantile group", is responsible for matters concerning drivers' licenses, administering driving and theoretical tests, issuing paperwork for vehicles, and providing other services for clients who approached their counter. The second, known as the "vehicle group", works with mechanical matters - checking vehicles, making sure they meet international standards. Common to both functional groups is their concern for road safety, which includes being updated on Norwegian and international legislation and ensuring high-quality service.

\section{Results}

Throughout the project, the participants reported feeling detached because they were engrossed in their daily work; they considered other matters to be simply more pressing than the intangible project goals. The researchers observed that some employees did not commit fully to the project, which resulted in processes not being entirely successful - the participants reported that there were only a limited number of successful changes during and after the project. The research identified eight recurring reasons that employees gave for not participating, which are discussed in connection with the following dimensions.

\section{Political Pressures}

Local managers, employees, and union reps were participating in local development projects (pilots) which entailed that groups with different positions collectively chose development actions to be carried out locally. The development actions varied across the groups; some 
examples were the development of a better procedure for meetings, visiting other functional groups or traffic stations for knowledge sharing, and acquiring new competencies in order to take on different or more varied work tasks.

One of the pilots involved participants acquiring the competencies required to process the two different bases of clients. At traffic stations, employees typically work at one of the counters: vehicles or drivers' licenses. On some days, one of the counters might be busier than the other, so being able to attend to different types of clients would make a traffic station more effective and ultimately more productive; as a result, clients would be served more quickly and the queue would be shorter. Several employees said that they felt positive about the possibility of acquiring a new competency and knowledge, and potentially getting more varied day-to-day work in the future. After some time, though, their commitment tended to diminish over time. Three workers stated why they found it difficult to take an active role:

We were not sure about what this meant, if it would be an extra burden. Were we supposed to do all this work, just so that our manager could cut down on the need for employees? We felt that we participated in something that could result in us losing our jobs [...] I am not sure if we had the wrong focus. We feel that we were guided by the facilitators into a path that eventually would lead to the reduction of our workplace, in a way. To be a part of becoming multidisciplinary. We were feeling misguided. (Worker G)

I feel like, participating in this development project leads to a need for fewer workers. That might mean that some people will lose their jobs [...] This was not something we wanted to work with. We wanted to work on our communication skills. (Worker $\mathrm{H}$ ) It was something we never chose ourselves. The topic of becoming multidisciplinary was forced upon us by the facilitators $[\ldots]$ the facilitators were very set on working with becoming multidisciplinary. (Worker $\mathrm{K}$ )

Given the time and a chance to think this through, these workers realized that this development initiative seemed to work against what they thought was the goal of the initial TVD project. Instead of working towards stronger cooperative structures and knowledge sharing, the colleagues felt they contributed to an outcome that did not benefit them at all because these actions could eventually result in job losses. Consequently, employees started questioning why they chose this development action, and several of them also remembered that the majority of employees actually wanted to develop their communication skills. In effect, many employees withdrew and did not take an active role in the process even though employee participation and collective development were the main points of the project. Another employee, who took part in a different pilot project, also experienced some uncertainty related to the possible outcomes of developing work practices.

It is something about sitting there, participating in something that will shut down my own workplace, finding methods so that other people will be able to do my work. (Worker J)

The employees who realized what might be at stake took a step back and did not wholeheartedly embrace the development actions and changes. 


\section{Power Issues}

A union representative talked about his experiences of suggesting improvements to his managers and his fear of facing some negative consequences later on. Suggestions had been ignored or declared as irrelevant, and it was the personal risk that stopped him from sharing further suggestions or concerns:

When we do disagree, some things are being held against me personally, later on. It happens all too often [...] and it ended with my manager telling me that because of me reporting something, I should not expect any promotions here or even getting work elsewhere. [...] The reason why I am reporting something is not to make things better for me $[\ldots]$ it is to make the organization's reputation better. (Union rep I)

In this case, the employee's experience of giving suggestions showed that there was a risk of receiving negative feedback. Ultimately, this risk was perceived as too big, not only in terms of daily work but also future prospects. In the case of negative feedback, this was something all employees risked when they gave suggestions to higher-level managers.

During the development project, another union representative experienced that in reality managers did not take their suggestions into account. Decisions had either already been made, or, in other situations, managers would ask for the suggestions and opinions of those on the shop-floor without having any intention of really assessing them.

Let's say that something happens, and they [managers] want us to come with suggestions or give advice. It is just a charade, because the decision is already made. [...] I have had that perception for a long time. (Union rep II)

Thus, a question arose: If managers do not actually assess shop-floor suggestions, why should employees make them in the first place? The TVD project was presented as a bottom-up process in which the workers were supposed to be the "engine" and problem solvers. The actual experience illustrates a very different reality, where decisions were ultimately made at the top levels of the organization.

It became clear that not all employees subscribed to the proposed collective effort to share knowledge. One of the workers explained how knowledge sharing sometimes would not always benefit the employee in the long run:

It is a question of how much you are supposed to share. I won't benefit from it. It is a cruel thing to say, but knowledge is power. The more knowledge you possess, the more likely [it is] that you will keep your job in the case of downsizing. For example. I have experienced it before: I kept my job because of my knowledge, and someone else lost his job. [...] I know that I am not alone in thinking like this and they are not sharing all their knowledge. We are protecting what's ours, really. (Worker C)

This worker made it clear that the employees had different levels of experience or educational, and some were better than others at keeping themselves updated on important information. With this in mind, it was important to this employee that his position was safe and that others 
had to make sure they had the required knowledge and information to do their job - in his view, it would be unfair if "free riders" took shortcuts and relied on others to do the job.

This project also identified another power struggle. Namely, In line with the participative approach, managers had to give their employees more responsibility and make them accountable. This entailed sharing more information and giving some of the managers' work tasks to employees. Not all the managers found this easy to do, and some carried on as before. It is thus questionable whether this was also, like Worker C's experience, the manager's way of protecting his or her position and power, as it was likely that sharing more information and work tasks with employees could have resulted in less-hierarchical structures.

\section{Demanding Parallel Project}

A frequently mentioned reason for not participating in the project was a lack of time and resources. Many participants reported that there were simply other matters that were too important to set aside, and that they could not simply shut the shop for a day or two in order to work on development or reflect on current practices.

There have been a lot of meetings. We already have enough to do, as it is. (Worker E)

Knowledge sharing has not increased. When I have finished this, I will continue with my own work... There is a lot that needs to be done... That's really what the days revolve around. (Worker C)

This is something we have to do on the side. No manager would be willing to put aside one hour a day for each of us to work on this. That would be a lot of hours. (Worker J)

We're at work and have our normal business to tend to. This is a side project. You don't get the opportunity to engage in it as much as you would like. (Worker L)

These workers shared the same frustrations as many others during the course of the project. The pilots were supposed to set aside time and resources in order to carry out at least four seminars each. In these seminars, the local manager and facilitators from the human resources department worked with employees and union reps to come up with development actions and better practices. This work would have to take place after office hours, because it would be impossible to do it with clients coming in. It is unsurprising that conducting a comprehensive development project might end up at the lower end of an employee's to-do list. Nevertheless, this project was given high priority on the managers' side. There were situations where, in order to carry out the pilot seminar, some of the traffic stations were allowed to shut down their services for a day or some other period of time. Historically, this was the first time a development project had received so much support and resources from higher level management.

Worker I spoke about how this type of development work required something different from their daily working life. The workers' experience points to challenges connected to the 
time needed to sit down with this type of work, but also the need to get into the "right mindset". This implies that a different type of mindset is required in order to work on development and reflect on improving existing practices.

When it's busy, this becomes a thing of lower priority. It demands something of you, right. You can't sit down for half an hour and come up with great ideas. You have to give it time and get into the mindset. (Worker I)

Supporting this experience, Worker D also talked about a different way of working from what he had been used to previously:

This is different from what I usually do at work. It's like group work at school. When I went to school, we didn't have much group work, like you would find for students nowadays. It's something completely different than what we, as mechanics, are used to.

It goes far beyond what we account for. (Worker D)

In the process of reflecting on current practices and coming up with development actions, several participants felt that it was very demanding to work on a process where the end result was not defined from the start. Managers and human resources facilitators would often say that it was all about "creating the road as we go", which made the participants frustrated. Employees were familiar with well-defined work tasks, both technical and mechanical, so this type of work demanded something different from them. They needed more time to get into the correct mindset, which not all of them felt they ever achieved. Several employees also talked about their daily work, in which they had always been occupied with improving their practices. In that sense, they felt there was no need for development seminars that were disconnected from their actual work.

\section{Beyond Established Work Descriptions}

The workers' experiences of being more involved and having more to say often very noticeably involved more work.

It's also a question about how many suggestions one should bring forward. It entails extra work. I already have enough to do in my day-to-day work. (Worker B)

If you take it upon yourself to remind your manager about the development actions, and what we are supposed to do, it will often become your job to initiate something. That is something I would like to avoid. (Worker D)

Well, we got to decide which development actions we wanted to work on, but nothing is happening. That is because our manager has a lot to do, so his perception is that we have to do it ourselves. (Worker M)

As the additional work stemming from the increased involvement and participation did not compromise well-defined tasks or did not fall into job descriptions or contracts, employees struggled with the difference between formal and informal demands. Some viewed the project as something additional, and not as the job they 
were originally hired to do, so they said that they should get higher salaries. In one manager's experience, the level of participation in development efforts among employees varied significantly:

There are big variations in how intensively employees participate in development efforts and in developing themselves. Some of them are satisfied with simply doing their job, [going] home and that's it. (Lower level manager I)

Here, the basic attitude was 'that's good enough', and certainly there was no willingness to do additional work. Especially for TVD, a public organization that for the most part deals with regulations and serving customers, the participative design during change did not seem to make employees more satisfied or even willing to participate more. To the employees, more participation involved more work and a completely different kind of work than what they were used to. It might be worth questioning whether the project design was developed to fit with the organizational structure, which in the case of TVD, strongly focuses on rules and regulations.

In the case of the TVD department, many employees have worked there for a long period of time. One manager expressed concern for these workers, as they often avoid any extra workload:

Those who have been employed here for 20-30 years are totally uninterested. They just do not want to. They know how to do their job. That's it. They do not want more to do. (Lower level manager II)

In many ways, this manager recognized that development efforts entailed more work for participating employees. His experience was that their engagement with participation was limited, as it would require their daily workload to increase and shake up the formerly established routines. Many TVD workers seemed satisfied with the status quo. The daily work routines and practices provided them with a sufficient amount of autonomy and the opportunity to participate, involving through union reps or managers if necessary.

It was expected that the participants would fully engage in the AR project if there had been a greater reward. The harsh reality of this seemed to be clear to many of the employees, as they reported that there were no rewards for giving suggestions or embracing the development process.

We will often have discussions about how to do things. [...] There is no reward for finding better solutions. (Worker B)

One of the workers spoke about being hesitant to take on an additional role in the department. The manager had offered employees the possibility to become multidisciplinary workers, which would entail acquiring the knowledge to be able to serve different groups of clients. As part of the development project, the need for more multidisciplinary workers was discussed across different traffic stations. In the case of Worker J, however, this development would also have required some changes connected to work descriptions and salaries before it could even be considered as desirable by employees.

I have been offered to become multidisciplinary. [...] there has to be some reward also and not only extra work on my behalf. [...] they have to consider increasing salaries and change work descriptions before I will consider it. (Worker J) 
Worker $\mathrm{C}$ had a different approach to this problem. As he explained, he had acquired additional competencies and knowledge at his own initiative. He was painfully aware that the problem would arise when extra work needed to be done, since this did not mean extra salary; furthermore, co-workers tended to take advantage of his efforts.

My experience is that I do not get paid for my knowledge. I read up on things while others benefit [from] that when they make decisions. In a professional sense, that's not okay. [...] I share with my colleagues when they ask [...] You get interrupted in your daily work, and if that happens it becomes an extra burden. (Worker C)

As the efforts required when engaging in development and participative activities were not being rewarded, or were considered as beyond his "normal" workload, Worker C clearly did not see many benefits from this type of work.

\section{Conclusion and Discussion}

This paper aims to show that employees might have rational reasons for not participation in an $\mathrm{AR}$ project. The findings make it clear that employee participation in AR-inspired projects should not be taken for granted due to the fact that prospective participants may have, from their own perspectives, rational reasons to withhold their engagement. Building on Table 1, the reasons encountered in the case of the TVD-project are summarized and categorized in Table 4.

It follows from this categorization that for all motives put forward for people to participate in AR, at least some participants in the TVD-project had their reservations about becoming involved. We found that many reasons put forward by participants fit well within the categorization of AR ideal perspectives as laid out in Table 1. The inductive approach to analyze the data resulted in additional practical implications which also could help explain the non-participation - namely; that the AR project was time consuming, that knowledge is power (which participants protect), participating may jeopardize job positions and that employees risk negative feedback when applying the voice that is given to them. The findings may point to a number of underlying issues within the department, including a possible lack of trust between management and employees. We acknowledge that the horse may refuse to drink the water out of fear that it is contaminated, to paraphrase the proverb. As a remedy, concrete

Table 4 Rational reasons for non-participation

\begin{tabular}{|c|c|c|}
\hline $\begin{array}{l}\text { AR } \\
\text { perspective }\end{array}$ & Motivation & Rational reasons \\
\hline Reflection & $\begin{array}{l}\text { Sharing knowledge } \\
\text { Questioning current practices } \\
\text { Joint efforts between practitioners and } \\
\text { researchers }\end{array}$ & $\begin{array}{l}\text { Requires a different mindset } \\
\text { Satisfied with status quo }\end{array}$ \\
\hline Action & $\begin{array}{l}\text { Improving current practices collectively } \\
\text { Developing improved services }\end{array}$ & $\begin{array}{l}\text { More work } \\
\text { No rewards }\end{array}$ \\
\hline Democracy & $\begin{array}{l}\text { Broad participation } \\
\text { Opportunity to make suggestions for } \\
\text { improvement } \\
\text { Having a say in the decision-making } \\
\text { Creating joint vision(s) }\end{array}$ & $\begin{array}{l}\text { Decisions are already made } \\
\text { Labor-management cooperation is perceived as a } \\
\text { charade }\end{array}$ \\
\hline
\end{tabular}


measures are called for rather than an abstract appeal to trust. Prospective participants' interests should be acknowledged and credible safeguards have to be built how adverse consequences will be handled, should they occur. To give an example from a related participative concept, namely continuous improvement: this can only be sustained if employees are given some kind of employment security so that they will not "engineer themselves out of a job" (Ichniowski and Shaw 2000: 348).

An issue, of course, is to what extent these findings are relevant beyond the TVD project itself. The project, like any other project, had its limitations and could be criticized for failing to engage all participants, and thus not complying with the AR ideal. Whilst the particular ways that employees' reasons for non-participation are TVD-specific, the phenomenon that employees have their own individual interests is general and will play a role in any project and organization.

One of Neumann's (1989) recommendations for the future was to publicly acknowledge and account for the fact that conflicting interests exist next to common ones. The TVD project illustrates that Neumann's statements are still relevant. Putting ideals into practice inevitably means compromising, and AR-inspired organizational development projects are good examples of that. Organizations are hierarchies in which actors with partly common and partly conflicting interests meet. This turns organizations into political arenas, in which the agendas tend to be set at the top of the hierarchy. Obviously, there is a tension with the democratic motivation of AR.

Participation can be stimulated based on a realistic perspective, keeping in mind the limitations and taking into account the actors and arenas involved. For one thing, to paraphrase Neumann, AR projects might start with the question "Why would these employees participate in the first place?" rather than assuming that they will.

Acknowledgements We would like to thank the participants in the presented case for their contribution to our research. We would also like to thank the reviewers and Editor-in-Chief Robert Flood, as well as our colleagues Hanne G. Finnestrand, Ola E. Vie and Jonas A. Ingvaldsen, and discussants at PhD seminar Lars Klemsdal and Thomas Laudal for their constructive and insightful comments on earlier drafts of this paper.

Author contributions The first author collected data and wrote most of the text. The second author provided a reflective outsider perspective, helped analyzing and interpret the data, and revising the text.

Funding Information Open Access funding provided by NTNU Norwegian University of Science and Technology (incl St. Olavs Hospital - Trondheim University Hospital).

Open Access This article is licensed under a Creative Commons Attribution 4.0 International License, which permits use, sharing, adaptation, distribution and reproduction in any medium or format, as long as you give appropriate credit to the original author(s) and the source, provide a link to the Creative Commons licence, and indicate if changes were made. The images or other third party material in this article are included in the article's Creative Commons licence, unless indicated otherwise in a credit line to the material. If material is not included in the article's Creative Commons licence and your intended use is not permitted by statutory regulation or exceeds the permitted use, you will need to obtain permission directly from the copyright holder. To view a copy of this licence, visit http://creativecommons.org/licenses/by/4.0/.

\section{References}

Baldwin M (2002) Co-operative inquiry as a tool for professional development. Syst Pract Act Res 15:223-235. https://doi.org/10.1023/A:1016392325258 
Baskerville RL (1997) Distinguishing action research from participative case studies. J Syst Inf Tech 1:24 43. https://doi.org/10.1108/13287269780000733

Brydon-Miller M, Greenwood D, Maguire P (2003) Why action research? Action Res 1:9-28. https://doi. org/10.1177/14767503030011002

Busck O, Knudsen H, Lind J (2010) The transformation of employee participation: Consequences for the work environment. Econ Ind Democracy 31:285-305. https://doi.org/10.1177/0143831X09351212

Cheney G (1995) Democracy in the workplace: Theory and practice from the perspective of communication. J Appl Commun Res 23:167-200. https://doi.org/10.1080/00909889509365424

Deetz S (1992) Democracy in an age of corporate colonialism: Developments in communication and the politics of everyday life. State University of New York Press, Albany

Dent EB, Goldberg SG (1999) Challenging "Resistance to Change". J Appl Behav Sci 35: 25-41. https://doi. org/10.1177/0021886399351003

Dewing J, Traynor V (2005) Admiral nursing competency project: Practice development and action research. J Clin Nurs 14:695-703. https://doi.org/10.1111/j.1365-2702.2005.01158.x

Eikeland O (2012) Action research and organizational learning: A Norwegian approach to doing action research in complex organizations. Edu Act Res 20:267-290. https://doi.org/10.1080/09650792.2012.676303

Emery FE, Purser R (1995) The search conference. San Francisco, Jossey-Bass

Friedman VJ (2001) Action science: Creating communities of inquiry in communities of practice. In: Reason P, Bradbury H (eds) Handbook of action research. Sage Publications Ltd, London, pp 160-170

Gaventa J, Cornwall A (2006) Challenging the boundaries of the possible: Participation, knowledge and power. IDS Bul 37:122-128. https://doi.org/10.1111/j.1759-5436.2006.tb00329.x

Gioia DA, Corley KG, Hamilton AL (2013) Seeking qualitative rigor in inductive research: Notes on the Gioia methodology. Organ Res Methods 16:15-31. https://doi.org/10.1177/1094428112452151

Godden NJ (2017) The participation imperative in co-operative inquiry: Personal reflections of an initiating researcher. Syst Pract Act Res 30:1-18. https://doi.org/10.1007/s11213-016-9387-2

Greenwood DJ, Levin M (2007) Introduction to action research: Social research for social change, 2nd edn. Sage, Thousand Oaks

Gustavsen B (2017) Action research and the promotion of democracy. Int J Act Res 2:101-111. https://doi. org/10.3224/ijar.v13i2.02

Gustavsen B, Pålshaugen $\varnothing$ (2015) How to succeed in action research without really acting: Tracing the development of action research to constructivist practice in organizational worklife. In: Bradbury $\mathrm{H}$ (ed) The Sage handbook of action research. Sage, London, pp 409-416

Hall BL (2001) I wish there were a poem of practices of participatory research. In: Reason P, Bradbury H (eds) Handbook of action research. Sage, London, pp 171-178

Harrison J, Freeman R (2004) Is organizational democracy worth the effort? The Acad Manage Exec 18:49-52

Ichniowski C, Shaw K (2000) Quality Improvement Practices and Innovative HRM Practices; New Evidence on Adoption and Effectiveness. In: Cole RE, Scott WR (eds) The Quality Movement \& Organization Theory. Thousand Oaks / London / New Delhi, Sage, pp 347-366

Kristiansen M, Bloch-Poulsen J (2017) participation and social engineering in early organizational action research: Lewin and the Harwood studies. Int J Act Res 2:154-177. https://doi.org/10.3224/ijar.v13i2.05

McLagan P, Nel C (1995) The age of participation: New governance for the workplace and the world. BerrettKoehler Publishers, San Francisco

Melin U, Axelsson K (2016) Action in action research: Elaborating the concepts of action, roles and dilemmas in a public e-service development project. J Syst Inf Tech 18:118-147. https://doi.org/10.1108/JSIT-10-2015-0074

Mumford E (2001) Advice for an action researcher. Inform Tech People 14:12-27. https://doi.org/10.1108 /09593840110384753

Neumann JE (1989) Why people don't participate in organizational change. Res Organ Chang Dev 3:181-212

Pateman C (1970) Participation and democratic theory. Cambridge University Press, Cambridge

Reason P (1999) Integrating action and reflection through co-operative inquiry. Manage Learn 30:207-225. https://doi.org/10.1177/1350507699302007

Reason P (2014) Justice, sustainability and participation. Int J Act Res 10:284-309

Reason P, Bradbury H (2001) Inquiry and participation in search of a world worthy of human aspiration. In: Reason P, Bradbury H (eds) Handbook of action research. Sage, London, pp 1-14

Simonsen J (2009) A concern for engaged scholarship: The challenges for action research projects. Scand J Inf Tech 21:111-128

Titchen A, Binnie A (1993) Research partnerships: collaborative action research in nursing. J Adv Nurs 18:858865. https://doi.org/10.1046/j.1365-2648.1993.18060858.x

Wenger E (1998) Communities of practice: Learning, meaning and identity. Cambridge University Press, Cambridge 